\title{
RANCANGAN SISTEM PORTAL NILAI SISWA BERBASIS WEB PADA MADRASAH DTA NURUL HIDAYAH
}

\section{Warja Dipura, Endang}

Fakultas Sains dan Teknologi, Universitas Panca Sakti Bekasi, Jawa Barat, Indonesia

Email: babang.juu@gmail.com, endangajah2018@gmail.com

\begin{tabular}{ll}
\hline INFO ARTIKEL & ABSTRAK \\
\hline Diterima & Seiring dengan pesatnya perkembangan teknologi dizaman sekarang, \\
22 Desember 2020 & makin banyak manusia yang seakan tidak bisa lepas dari teknologi. \\
Direvisi & Segala aktivitas sudah dilakukan dengan memanfaatkan kemajuan \\
6 Januari 2021 & teknologi. Salah satunya adalah dalam bidang informasi yang \\
Disetujui & memanfatkan perkembangan teknologi. Tak bisa dipungkiri bahwa \\
10 Januari 2021 & informasi dizaman sekarang sangatlah penting bagi kehidupan \\
\hline Kata Kunci: & manusia. Namun dibalik perkembangan teknologi yang sangat pesat, \\
Sistem; Data Nilai; & masih banyak orang yang belum bisa memanfaatkannya. Dalam hal \\
Web & ini mengenai data nilai siswa yang ada di Madrasah DTA Nurul \\
& Hidayah yang masih menggunakan sistem manual. Ditemukan \\
& banyak sekali kekurangan dalam penggunaan sistem dengan cara \\
& manual. Diantaranya seperti waktu yang kurang efisien dan \\
& keakuratan data. Maka penelitian ini akan membahas tentang data \\
& nilai siswa. Dengan adanya sistem berbasis web tentunya diharapkan \\
& dapat mempermudah dalam pendataan nilai siswa.
\end{tabular}

Keywords:

ABSTRACT

Along with the rapid development of technology today, more and more people seem to be inseparable from technology. All activities have been carried out by utilizing technological advances. One of them is in the field of information that utilizes technological developments. It is undeniable that information nowadays is very important for human life. But behind the very rapid development of technology, there are still many people who have not been able to System; Value Data; take advantage of it. In this case, the data on student scores in Madrasah DTA Nurul Hidayah is still using the manual system. Web Found many shortcomings in using the system manually. Among them are less efficient time and data accuracy. So this study will discuss the data on student scores. With a web-based system, of course, it is hoped that it will make it easier to collect student score data.

\section{Pendahuluan}

Lembaga pendidikan saat ini terus mengalami perkembangan pesat seiring dengan laju perkembangan Teknologi
Informasi yang sangat beraneka ragam (Husaini, 2017). Peningkatan kualitas dan mekanisme pelayanan di bidang pendidikan sangat diperlukan agar lebih berdaya guna 
dan berhasil guna, sehingga Sumber Daya Manusia (SDM) yang diciptakan dapat berpartisipasi dalam membangun masyarakat sesuai dengan kemampuannya (Neolaka, 2020). Namun masih banyak yang belum bisa menerapkan sistem komputerisasi dan lebih memilih menggunakan sistem manual (Setiawan et al., 2017).

DTA Nurul Hidayah termasuk satuan pendidikan keagamaan islam nonformal setara dengan sekolah dasar, yang menyelenggarakan pendidikan agama islam sebagai pelengkap bagi siswa pendidikan umum yang sistem pendataan nilai siswanya masih terbilang manual. Sudah sepantasnya diera yang serba canggih ini, setiap sekolah ataupun yayasan menggunakan media internet atau sistem yang sudah terkomputerisasi agar lebih efektif dan memudahkan dalam pendataan nilai siswa.

Permasalahan yang sering ditemui dalam sistem manual yaitu proses penilaian yang memakan banyak waktu. Belum lagi nilai-nilai yang harus dikalkulasi oleh guru yang menjadi kurang efisien (Padeli et al., 2020).

Penelitian ini bermaksud dan bertujuan yang diharapkan berjalan dengan baik. Adapun maksud dari penelitian ini adalah :

1 Merancang sistem pendataan nilai siswa berbasis web

2 Memudahkan guru menyimpan data siswa dan data nilai siswa sekaligus menyampaikan nilai siswa secara efektif

\section{Metode Penelitian}

\section{A. Tahapan Penelitian}

1 Requirement, mempersiapkan dan menganalisa kebutuhan dari software yang akan dikerjakan. Informasi dan insight yang diperoleh dapat berupa dari hasil wawancara, survei, studi literatur, observasi, hingga diskusi. Biasanya di dalam sebuah perusahaan, tim analis akan menggali informasi sebanyak - banyaknya dari klien atau user yang menginginkan produk beserta dengan kebutuhan sistemnya (Nugraha, 2011).

2 Design Pembuatan desain aplikasi sebelum masuk pada proses coding. Tujuan dari tahap ini, supaya mempunyai gambaran jelas mengenai tampilan dan antarmuka software yang kemudian akan dieksekusi oleh tim programmer. Untuk proses ini, akan berfokus pada pembangunan struktur data, arsitektur software, perancangan interface (Yanuarti, 2017).

3 Implementasi kode program dengan menggunakan berbagai tools dan bahasa pemrograman sesuai dengan kebutuhan tim dan perusahaan. Di dalam tahap pengembangan, biasanya dibagi lagi menjadi 3 tim yang memiliki tugas yang berbeda. Pertama ada front end (untuk client side), backend (untuk server side), dan full stack (gabungan antara front end dan backend). Selain itu, pada tahap ini juga dilakukan pemeriksaan lebih dalam terkait dengan modul yang sudah dibuat, apakah berjalan dengan semestinya atau tidak

4 Integration \& Testing, setelah proses integrasi sistem telah selesai, berikutnya masuk pada pengujian modul. Yang bertujuan untuk mengetahui apakah perangkat lunak sudah sesuai dengan desain, dan fungsionalitas dari aplikasi apakah berjalan dengan baik atau tidak. Jadi, dengan adanya tahap pengujian, maka dapat mencegah terjadinya kesalahan, bug, atau error pada program sebelum masuk pada tahap produksi. Orang yang bertanggung jawab untuk melakukan testing adalah QA (Quality Assurance) dan QC (Quality Control) (Muljo \& Darmadi, 2009). 
5 Operation \& Maintenance, Setelah dilakukan pengujian sistem, maka akan masuk pada tahap produk dan pemakaian perangkat lunak oleh pengguna (user). Untuk proses pemeliharaan, memungkinkan pengembang untuk melakukan perbaikan terhadap kesalahan yang ditemukan pada aplikasi setelah digunakan oleh user (Hidayat \& Muttaqin, 2020).

Dalam pengembangan sistem, penulis menggunakan metode pemodelan sistem dengan model analisis terstruktur hanya dengan menggunakan Flowchart (Nassi \& Shneiderman, 1973). Diagram alir atau Flowchart merupakan bagan yang memperlihatkan urutan dan hubungan antar proses beserta instruksinya (Ensmenger, 2016). Fungsinya adalah memberikan gambaran secara garis besar untuk program atau aplikasi yang dibuat. Flowchart dapat dibedakan ke dalam tiga kategori yaitu Flowchart dokumen.

\section{Hasil dan Pembahasan}

\section{A. Hasil Penelitian}

1 Rencana Kebutuhan (Requirement Planning)

Pada tahap pengumpulan kebutuhan ini, penulis dan kepala sekolah Madrasah DTA Nurul Hidayah sebagai pihak yang terlibat dalam penelitian ini melakukan komunikasi untuk mengidentifikasikan kebutuhankebutuhan data yang diperlukan untuk membangun sistem portal nilai siswa pada Madrasah DTA Nurul Hidayah. Setelah membicarakan tujuan-tujuan dari aplikasi yang akan dibuat selanjutnya penulis dan kepala sekolah Madrasah DTA Nurul Hidayah menentukan informasi-informasi apa saja yang dibutuhkan dalam pembuatan aplikasi yang akan dibuat. Adapun hasil dari wawancara yang di dapat penulis adalah sebagai berikut:

Sistem yang sedang berjalan berjalan pada Madrasah DTA Nurul Hidayah sebagai berikut

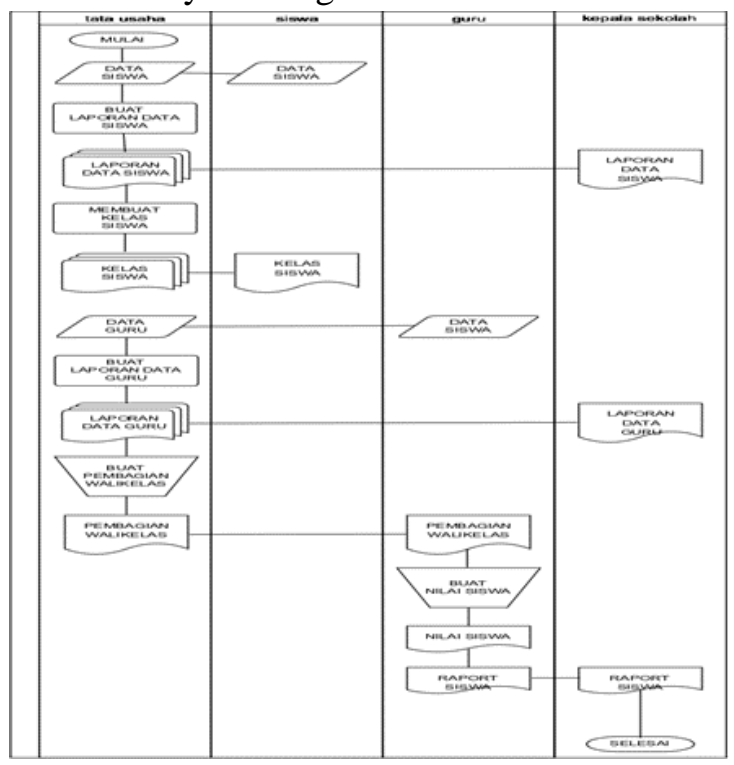

Gambar 1

Flowchart Sistem Yang Berjalan

Hasil analisis kebutuhan yang diperoleh terdiri dari dari kebutuhan pengguna, kebutuhan aplikasi, kebutuhan perangkat keras, kebutuhan perangkat lunak. Kebutuhan-kebutuhan tersebut sebagai berikut:

\section{a Kebutuhan Pengguna}

1) Kebutuhan Admin. Admin dapat mengelola data user, data mata pelajaran, data kelas, data ekstrakulikuler, data siswa, data absensi, data guru, data pengajar, data walikelas, data kepala sekolah dan .log out.

2) Kebutuhan Guru. Guru dapat mengelola data kenaikan kelas, data peserta ekstrakulikuler, data penilaian mapel, data peringkat siswa dan log out.

3) Kebutuhan Siswa. Siswa dapat melihat data nilai raport. 
4) Kebutuhan Kepala Sekolah. Kepala Sekolah dapat mengelola data user, data mata pelajaran, data kelas, data ekstrakulikuler, data siswa, data absensi, data guru, data pengajar, data walikelas, data kepala sekolah dan .log out.

b Kebutuhan Aplikasi

1) Admin, yang akan dilakukan oleh admin meliputi penginputan data user, data mata pelajaran, data kelas, data ekstrakulikuler, data siswa, data absensi, data guru, data pengajar, data walikelas, data kepala sekolah dan .log out.

2) Guru akan mengelola data kenaikan kelas, data peserta ekstrakulikuler, data penilaian mapel, data peringkat siswa dan log out.

3) Siswa berisi informasi data nilai raport.

4) Kepala Sekolah mengelola data master sekolah yang akan dilakukan oleh admin. Meliputi penginputan data user, data mata pelajaran, data kelas, data ekstrakulikuler, data siswa, data absensi, data guru, data pengajar, data walikelas, data kepala sekolah dan .log out

c Kebutuhan Perangkat Keras

1) Unit CPU (Central Processing Unit)

2) Keyboard dan Mouse

3) Kebutuhan Perangkat Lunak Adapun spek

minimum perangkat lunak yang di butuhkan adalah:

1) Windows 10

2) Database MySQL

3) Webserver apache

2 Proses Desain Sistem (Design System)

Pada tahap ini penulis melakukan perancangan aplikasi menggunakan flowchart, usecase diagram, class diagram, activity diagram dan sequence diagram. Selanjutnya penulis melakukan perancangan database dan design interface (antarmuka).

3 Activity Diagram

Diagram aktivitas dari Sistem portal nilai siswa Madrasah DTA Nurul Hidayah dapat dilihat pada gambar berikut :

a. alur dari proses sistem yang dilakukan oleh aktor admin pada Sistem Portal Nilai Siswa Madrasah DTA Nurul Hidayah, berikut penjelasannya :

1) Aktor admin melakukan start dengan melanjutkan ke aktivitas login.

2) Setelah itu pada sistem melakukan identifikasi akun apabila akun yang dimasukkan benar maka akan masuk kedalam menu utama dan apabila akun yang dimasukkan salah akan balik ke dalam aktivitas menu login.

3) Pada tampilan utama, aktor admin dapat melakukan aktivitas mengelola data user, data mata pelajaran, data kelas, data ekstrakulikuler, data siswa, data absensi, data guru, data pengajar, data walikelas, data kepala sekolah

4) Kemudian dari aktivitas tersebut aktor admin dapat melakukan logout dari akun yang telah $\operatorname{login}$.

b. Alur dari proses sistem yang dilakukan oleh aktor guru pada Sistem Portal nilai siswa Madrasah DTA Nurul Hidayah, berikut penjelasannya

1) Aktor guru melakukan start dengan melanjutkan ke aktivitas login. 
2) Setelah itu pada sistem melakukan identifikasi pada akun apabila akun yang dimasukkan benar maka akan masuk ke dalam menu utama dan apabila akun yang dimasukkan salah akan balik ke dalam aktivitas menu login.

3) Pada tampilan utama, aktor guru dapat melakukan aktivitas input data kenaikan kelas siswa, input data nilai peserta ekstrakulikuler, input data penilaian siswa, dan melihat data peringkat siswa.

4) Kemudian dari aktivitas tersebut aktor guru dapat melakukan logout dari akun yang telah login

c. Proses sistem yang dilakukan oleh aktor siswa pada Sistem Portal Nilai Siswa Madrasah DTA Nurul Hidayah, berikut penjelasannya :

1) Aktor siswa melakukan start dengan melanjutkan ke aktivitas login.

2) Setelah itu pada sistem melakukan identifikasi pada akun apabila akun yang dimasukkan benar maka akan masuk ke dalam menu utama dan apabila akun yang dimasukkan salah akan balik ke dalam aktivitas menu login.

3) Pada tampilan utama, aktor siswa dapat melakukan aktivitas melihat Raport meliputi nilai mapel, nilai ekstrakulikuler dan nilai absensi.

4) Kemudian dari aktivitas tersebut aktor siswa dapat melakukan logout dari akun yang telah login.

d. Alur dari proses sistem yang dilakukan oleh aktor kepala sekolah pada Sistem portal nilai siswa, berikut penjelasannya :

1) Aktor Kepala sekolah melakukan start dengan melanjutkan ke aktivitas login.

2) Setelah itu pada sistem melakukan identifikasi akun apabila akun yang dimasukkan benar maka akan masuk kedalam menu utama dan apabila akun yang dimasukkan salah akan balik ke dalam aktivitas menu login.

3) Pada tampilan utama, aktor kepala sekolah dapat melakukan aktivitas mengelola data user, data mata pelajaran, data kelas, data ekstrakulikuler, data siswa, data absensi, data guru, data pengajar, data walikelas, data kepala sekolah

4) Kemudian dari aktivitas tersebut aktor kepala sekolah dapat melakukan logout dari akun yang telah login.

B. Pembahasan

1) Rancangan Tampilan Login

Rancangan tampilan login akan menampilkan login untuk login ke halaman worksheet seperti gambar berikut

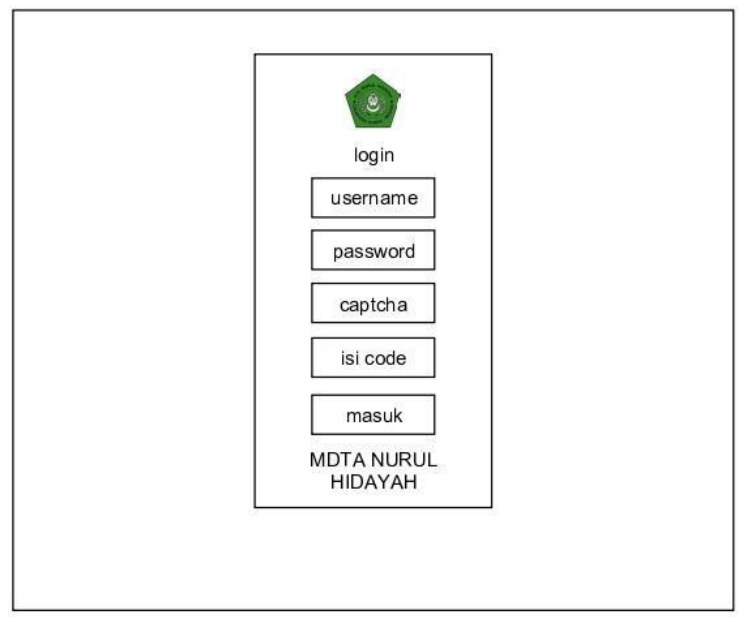

Gambar 2

Rancangan Tampilan Login 
2) Rancangan Tampilan Menu Admin Rancangan tampilan menu admin adalah rancangan tampilan interface untuk akses admin yang terdiri dari menu data user, data mata pelajaran, data kelas, data ekstrakulikuler, data siswa, data absensi, data guru, data pengajar, data walikelas, kepala sekolah. Berikut adalah design interface halaman pada admin.

a. Rancangan Menu Data User pada bagian Admin

Rancangan menu data user pada bagian admin merupakan rancangan yang dibuat untuk admin guna menampilkan data user sekaligus menginput data user, berikut rancangannya dapat dilihat pada gambar

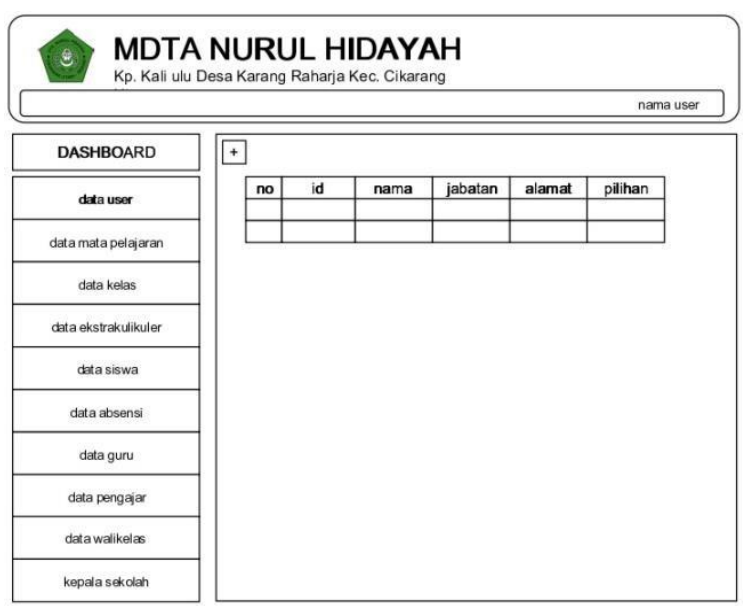

Gambar 3

Rancangan Menu Data User pada bagian Admin

3) Rancangan Tampilan Menu Guru Rancangan tampilan menu guru adalah rancangan tampilan interface untuk akses guru yang terdiri dari menu Kenaikan kelas, Peserta Ekstrakulikuler, Penilaian, dan laporan peringkat siswa.

4) Rancangan Tampilan Menu Siswa
Rancangan tampilan menu siswa adalah rancangan tampilan interface untuk akses siswa yang terdiri dari menu data Raport dan rincian nilai raport

5) Rancangan tampilan menu kepala sekolah

Rancangan tampilan menu kepala sekolah adalah rancangan tampilan interface untuk akses kepala sekolah yang terdiri dari menu data user, data mata pelajaran, data kelas, data ekstrakulikuler, data siswa, data absensi, data guru, data pengajar, data walikelas, dan kepala sekolah. Berikut adalah design interface halaman pada kepala sekolah.

C. Tahap Implementasi Sistem

Pada tahap ini, jika aplikasi sistem portal nilai pada Madrasah DTA Nurul Hidayah yang telah diuji dan diterima, siap untuk diterapkan di Madrasah DTA Nurul Hidayah. Dan berikut hasil dari implementasi sistem yang sudah penulis buat.

1. Tampilan Halaman Login

Pada tampilan ini berisikan form login untuk masuk kedalam dashboard dengan cara mengisi field username, password dan memilih akses masuk lalu menekan tombol login yang terdapat pada tampilan form yang dapat dilihat pada gambar

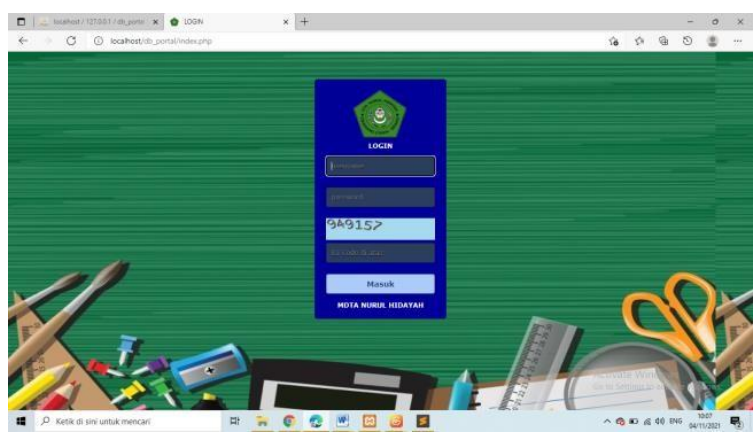

Gambar 4

Tampilan Halaman Login 
2. Tampilan Halaman Admin

Tampilan halaman admin adalah tampilan interface untuk akses admin yang terdiri dari menu data user, data mata pelajaran, data kelas, data ekstrakulikuler, data siswa, data absensi, data guru, data pengajar, data walikelas, dan data kepala sekolah.

3. Tampilan Halaman Guru

Tampilan halaman guru adalah tampilan interface untuk akses guru yang terdiri dari menu kenaikan kelas, peserta ekstrakulikuler, penilaian mapel dan laporan peringkat. Berikut adalah tampilan halaman pada guru.

\section{Tampilan Halaman Siswa}

Tampilan halaman siswa adalah tampilan interface untuk akses siswa yang terdiri dari menu Raport dan rincian nilai raport.

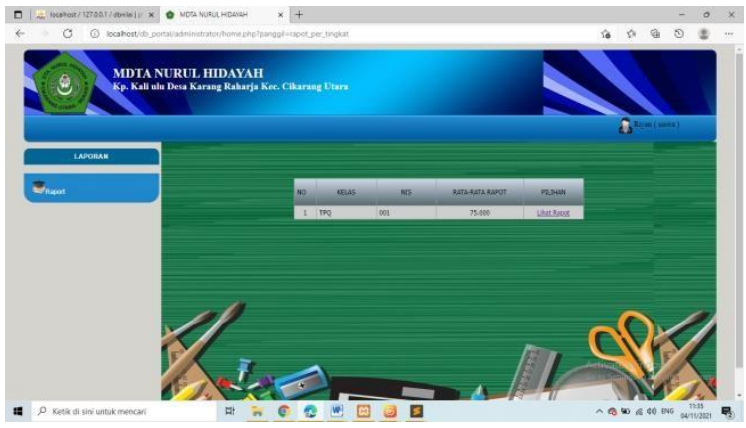

\section{Gambar 5}

Tampilan Halaman Raport Pada Bagian Siswa

5. Tampilan Halaman Kepala Sekolah

Tampilan halaman kepala sekolah adalah tampilan interface untuk akses kepala sekolah yang terdiri dari menu data user, data mata pelajaran, data kelas, data ekstrakulikuler, data siswa, data absensi, data guru, data pengajar, data walikelas dan data kepala sekolah.

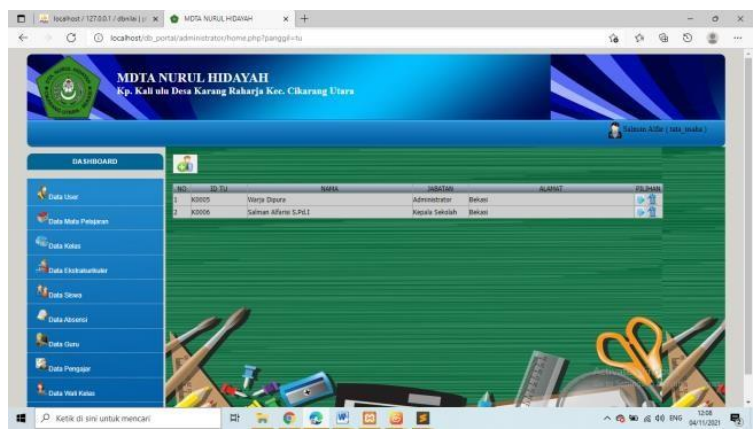

Gambar 6 Tampilan Halaman User Pada

Bagian Kepala Sekolah

D. Pembahasan Penelitian

Sistem Portal Nilai siswa pada Madrasah DTA Nurul Hidayah memberikan suatu sistem yang sudah terkomputerisasi kepada semua yang terkait pada Madrasah DTA Nurul Hidayah baik bagi TU, guru, siswa dan orang tua. Sistem ini dikembangkangkan menggunakan Waterfall, dimana waterfall ini terdapat 5 (lima) tahapan diantaranya yaitu Requirement, Desain, Implementation, Integration/Testing dan Operation/Maintenance.

1. Pengujian Sistem, pada tahapan ini, penulis melakukan pengujian sistem dengan menggunakan pengujian blackbox testing.

2. Pengujian Menu Login

Berikut dapat dilihat pengujian dari menu login, dapat dilihat pada tabel

Tabel 1

Pengujian Menu Login

\begin{tabular}{llll}
\hline Data Masuk & Hasil yang diharapkan & Hasil pengujian & Kesimpulan \\
\hline Klik button login & Menampilkan menu home & Sesuai harapan & Berhasil \\
\hline
\end{tabular}


3. Pengujian Menu di Dashboard Admin

Tabel 2

Pengujian Menu di Dashboard Admin

\begin{tabular}{|c|c|c|c|}
\hline Data Masuk & Hasil yang diharapkan & Hasil pengujian & Kesimpulan \\
\hline Klik menu data user & Menampilkan menu data user & Sesuai harapan & Berhasil \\
\hline Klik menu data mata pelajaran & $\begin{array}{l}\text { Menampilkan menu data mata } \\
\text { pelajaran }\end{array}$ & Sesuai harapan & Berhasil \\
\hline Klik menu data kelas & Menampilkan menu data kelas & Sesuai harapan & Berhasil \\
\hline Klik menu data ekstrakulikuler & $\begin{array}{l}\text { Menampilkan } \\
\text { ekstrakulikuler }\end{array}$ & Sesuai harapan & Berhasil \\
\hline Klik menu data siswa & Menampilkan menu data siswa & Sesuai harapan & Berhasil \\
\hline Klik menu data absensi & Menampilkan menu data absensi & Sesuai harapan & Berhasil \\
\hline Klik menu data guru & Menampilkan menu data guru & Sesuai harapan & Berhasil \\
\hline Klik menu data pengajar & Menampilkan menu data pengajar & Sesuai harapan & Berhasil \\
\hline Klik menu data walikelas & Menampilkan menu data walikelas & Sesuai harapan & Berhasil \\
\hline Klik menu kepala sekolah & Menampilkan menu kepala sekolah & Sesuai harapan & Berhasil \\
\hline
\end{tabular}

4. Pengujian Menu di Dashboard Guru

Tabel 3

Pengujian Menu di Dashboard Guru

\begin{tabular}{llllll}
\hline Data Masuk & \multicolumn{2}{l}{ Hasil yang diharapkan } & \multicolumn{2}{l}{$\begin{array}{l}\text { Hasil } \\
\text { pengujian }\end{array}$} & Kesimpulan \\
\hline Klik menu kenaikan kelas & \multicolumn{2}{l}{ Menampilkan menu kenaikan kelas } & Sesuai harapan & Berhasil \\
\hline Klik menu peserta ekstrakulikuler & $\begin{array}{l}\text { Menampilkan } \\
\text { ekstrakulikuler }\end{array}$ & menu & peserta & Sesuai harapan & Berhasil \\
\hline Klik menu penilaian mapel & $\begin{array}{l}\text { Menampilkan } \\
\text { mapel }\end{array}$ & menu penilaian & Sesuai harapan & Berhasil \\
\hline Klik menu laporan peringkat & $\begin{array}{l}\text { Menampilkan } \\
\text { peringkat }\end{array}$ & menu & laporan & Sesuai harapan & Berhasil \\
\hline
\end{tabular}

5. Pengujian Menu di Dashboard Siswa

Tabel 4

Pengujian Menu di Dashboard Siswa

\begin{tabular}{llll}
\hline Data Masuk & Hasil yang diharapkan & Hasil pengujian & Kesimpulan \\
\hline Klik menu raport & Menampilkan menu raport & Sesuai harapan & Berhasil \\
\hline Klik rincian nilai raport & $\begin{array}{l}\text { Menampilkan } \\
\text { Rincian nilai raport }\end{array}$ & Sesuai harapan & Berhasil \\
& & & \\
\hline
\end{tabular}

6. Pengujian Menu di Dashboard Kepala

Sekolah

Tabel 5

Pengujian Menu di Dashboard Kepala Sekolah

\begin{tabular}{llll}
\hline Data Masuk & Hasil yang diharapkan & $\begin{array}{l}\text { Hasil } \\
\text { pengujian }\end{array}$ & Kesimpulan \\
\hline Klik menu data user & Menampilkan menu data user & Sesuai harapan & Berhasil \\
\hline Klik menu data mata pelajaran & $\begin{array}{l}\text { Menampilkan menu data mata } \\
\text { pelajaran }\end{array}$ & Sesuai harapan & Berhasil \\
\hline
\end{tabular}


Rancangan Sistem Portal Nilai Siswa Berbasis Web Pada Madrasah DTA Nurul Hidayah

\begin{tabular}{|c|c|c|c|}
\hline Klik menu data kelas & Menampilkan menu data kelas & Sesuai harapan & Berhasil \\
\hline Klik menu data ekstrakulikuler & $\begin{array}{l}\text { Menampilkan } \\
\text { ekstrakulikuler }\end{array}$ & Sesuai harapan & Berhasil \\
\hline Klik menu data siswa & Menampilkan menu data siswa & Sesuai harapan & Berhasil \\
\hline Klik menu data absensi & Menampilkan menu data absensi & Sesuai harapan & Berhasil \\
\hline Klik menu data guru & Menampilkan menu data guru & Sesuai harapan & Berhasil \\
\hline Klik menu data pengajar & Menampilkan menu data pengajar & Sesuai harapan & Berhasil \\
\hline Klik menu data walikelas & Menampilkan menu data walikelas & Sesuai harapan & Berhasil \\
\hline Klik menu kepala sekolah & Menampilkan menu kepala sekolah & Sesuai harapan & Berhasil \\
\hline
\end{tabular}

\section{Kesimpulan}

Berdasarkan analisis dan perancangan maka dapat disimpulkan beberapa berikut yaitu penggolongan user menjadi lima bagian (Siswa, Orang Tua Siswa, Guru, Kepala Sekolah, Administrator) dengan batasan akses tertentu dapat dikatakan pula sebagai pembagian hak, wewenang dan kewajiban user yang bersangkutan.

Sistem ini diharapkan mampu memudahkan pihak sekolah dalam mengawasi dan mengontrol absensi dan informasi nilai anak didik secara mudah dan cepat tanpa harus membuka buku besar.

Dikarenakan sistem informasi ini merupakan sebuah aplikasi berbasis web, maka sistem informasi ini dapat di-publish melalui jaringan internet. Sistem informasi ini memudahkan pihak orang tua siswa dalam mengawasi anaknya dalam hal kehadiran dan penilaian .Pihak sekolah dapat melakukan pendataan siswa, wali siswa, dan guru secara efektif dan efisien. Kekhawatiran akan rusaknya data apabila menggunakan buku besar dapat di-backup oleh sistem informasi yang sudah terkomputerisasi ini.

\section{Bibliografi}

Ensmenger, N. (2016). The multiple meanings of a flowchart. Information \& Culture, 51(3), 321-351.Google Scholar

Hidayat, T., \& Muttaqin, M. (2020). Pengujian sistem informasi pendaftaran dan pembayaran wisuda online menggunakan black box testing dengan metode equivalence partitioning dan boundary value analysis. Google Scholar

Husaini, M. (2017). Pemanfaatan teknologi informasi dalam bidang pendidikan (eeducation). MIKROTIK: Jurnal Manajemen Informatika, 2(1). Google Scholar

Muljo, H. H., \& Darmadi, H. (2009). Integrasi Sistem Informasi Puskesmas. CommIT (Communication and Information Technology) Journal, 3(1), 45-49. Google Scholar

Nassi, I., \& Shneiderman, B. (1973). Flowchart techniques for structured programming. ACM Sigplan Notices, 8(8), 12-26. Google Scholar

Neolaka, M. N. B. C. (2020). Pendidikan Dasar di Daerah Perbatasan: Potret dan Upaya Peningkatan Kualitasnya. Inteligensia Media. Google Scholar

Nugraha, D. W. (2011). Software requirement dalam membangun sistem informasi pelayanan publik. MEKTEK, 13(3). Google Scholar

Padeli, P., Ramadhan, G. K. H., \& Aprilyani, U. T. (2020). Perancangan Sistem Informasi Penilaian Siswa Berbasis Web Pada SMK Al-Husna Kota Tangerang. Technomedia Journal, 4(2 Februari), 155-169. Google Scholar

Setiawan, A., Suryani, N., \& Asrowi, A. (2017). Urgensi Pemanfaatan Multimedia dalam Pendidikan Islam. Prosiding Seminar Nasional Teknologi Pendidikan. Google Scholar 
Warja Dipura, Endang

Yanuarti, E. (2017). Desain Aplikasi

Scholar

Pengelolaan Laboratorium Komputer.

Jurnal Sisfokom (Sistem Informasi Dan

Komputer), 6(1), 60-66. Google

Copyright holder:

Warja Dipura, Endang (2021).

First publication right:

Action Research Literate

This article is licensed under:

(c) (i) (?) 